Elsevier Editorial System(tm) for Colloids and Surfaces A: Physicochemical and Engineering Aspects

Manuscript Draft

Manuscript Number: COLSUA-D-15-00703R1

Title: Gold(III) extraction and recovery and gold(III)/copper(II) separation using micelles

Article Type: Research Paper

Keywords: SDS, DTAC, PADA, MEUF, ultrafiltration, stripping

Corresponding Author: Prof. Fernando Secco, Ph.D.

Corresponding Author's Institution: University of Pisa

First Author: Sabriye Aydinoglu

Order of Authors: Sabriye Aydinoglu; Tarita Biver; Alessio Ceccarini; Fernando Secco, Ph.D.; Marcella Venturini

Abstract: Gold extraction from aqueous solutions has been performed by micellar enhanced ultrafiltration (MEUF), using SDS and DTAC micelles. DTAC entraps $92 \%$ to $100 \%$ of the metal, which is present in form of AuCl4-, owing to electrostatic interaction. Using SDS the extraction of gold is unsuccessful. However, addition of PADA, as a metal extractor agent, according to the ligand modified micellar enhanced ultrafiltration (LM-MEUF) procedure, makes the extraction yield to approach 100\% also with SDS. The recovery of gold entrapped in the micellar pseudo-phase has also been investigated. Different stripping agents have been used, the most efficient of them being a mixture of $\mathrm{NaCl}$ and $\mathrm{NH} 3$ which allowed the metal to be expelled from the micelle with a yield of $85 \%$. Finally, $\mathrm{Au}(\mathrm{III}) / \mathrm{Cu}$ (II) separation is achieved with DTAC or SDS between $\mathrm{pH} 3$ and 5 . Almost $100 \%$ of $\mathrm{Au}(\mathrm{III})$ is retained on DTAC micelles while all $\mathrm{Cu}(\mathrm{II})$ remains in the aqueous medium, while the opposite occurs in SDS. 


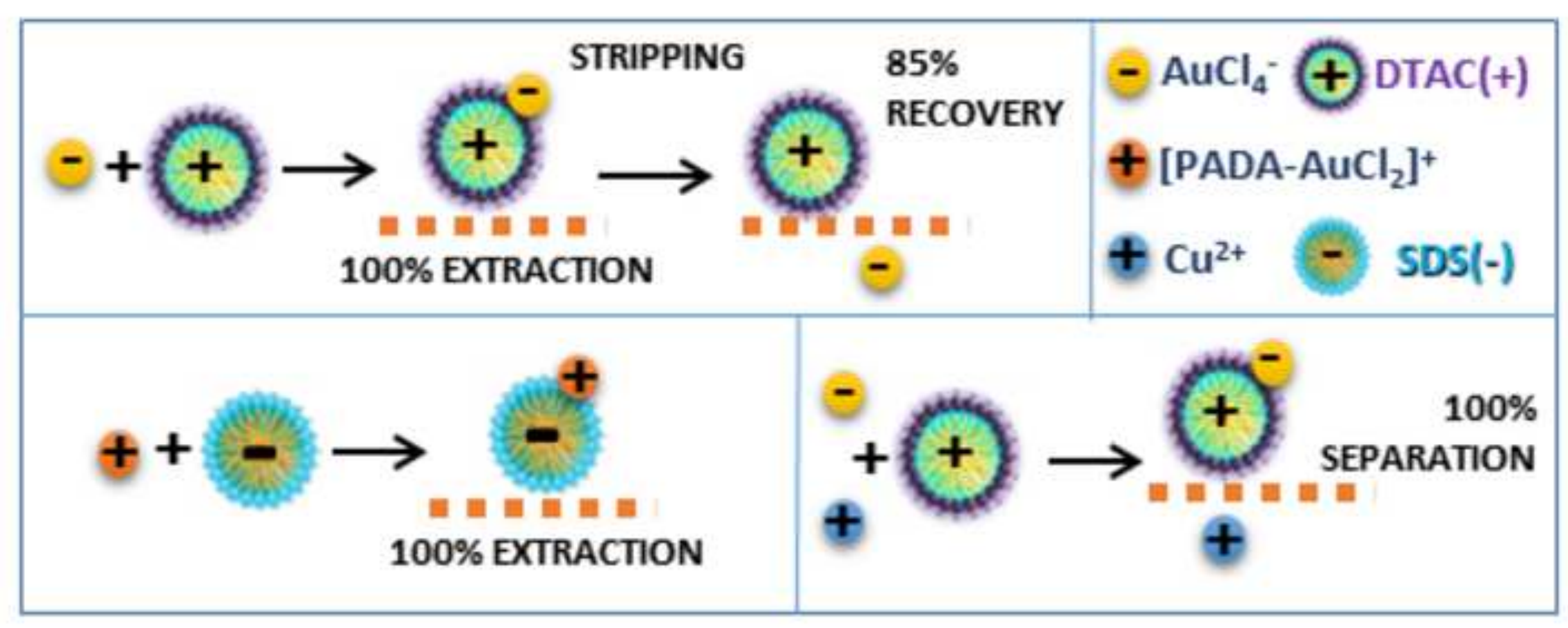




\section{HIGHLIGHTS}

- Micellar Enhanced UltraFiltration approach enables Au recovery and $\mathrm{Au} / \mathrm{Cu}$ separation

- DTAC(+) micelles extract $\mathrm{AuCl}_{4}{ }^{-}$with excellent yields

- $\mathrm{AuCl}_{4}{ }^{-}$can be recovered from DTAC with good yields using $\mathrm{NH}_{3} / \mathrm{NaCl}$ mixtures

- SDS(-) micelles extract the [PADA-AuCl $\left.]_{2}\right]^{+}$complex with excellent yields

- Excellent $\mathrm{AuCl}_{4}{ }^{-} / \mathrm{Cu}^{2+}$ separation is achieved using either DTAC or SDS 


\title{
Gold(III) extraction and recovery and gold(III)/copper(II) separation using micelles
}

\author{
Sabriye Aydinoglu', Tarita Biver, Alessio Ceccarini, Fernando Secco*, Marcella Venturini
}

Dipartimento di Chimica e Chimica Industriale, Università di Pisa - Via Moruzzi 3 - 56124 Pisa (Italy)

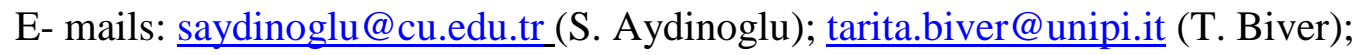
alessio.ceccarini@unipi.it (A.Ceccarini); fernando.secco@unipi.it (F. Secco); marcella@dcci.unipi.it (M. Venturini)

Corresponding Author: Fernando Secco, Dipartimento di Chimica e Chimica Industriale, Università di Pisa - Via Risorgimento 35 - 56122 - Pisa (Italy), fernando.secco@ unipi.it, +390502219259 .

\begin{abstract}
Gold extraction from aqueous solutions has been performed by micellar enhanced ultrafiltration (MEUF), using SDS and DTAC micelles. DTAC entraps $92 \%$ to $100 \%$ of the metal, which is present in form of $\mathrm{AuCl}_{4}{ }^{-}$, owing to electrostatic interaction. Using SDS the extraction of gold is unsuccessful. However, addition of PADA, as a metal extractor agent, according to the ligand modified micellar enhanced ultrafiltration (LM-MEUF) procedure, makes the extraction yield to approach $100 \%$ also with SDS. The recovery of gold entrapped in the micellar pseudo-phase has also been investigated. Different stripping agents have been used, the most efficient of them being a mixture of $\mathrm{NaCl}$ and $\mathrm{NH}_{3}$ which allowed the metal to be expelled from the micelle with a yield of $85 \%$. Finally, $\mathrm{Au}(\mathrm{III}) / \mathrm{Cu}(\mathrm{II})$ separation is achieved with DTAC or SDS between $\mathrm{pH} 3$ and 5. Almost $100 \%$ of $\mathrm{Au}(\mathrm{III})$ is retained on DTAC micelles while all $\mathrm{Cu}(\mathrm{II})$ remains in the aqueous medium, while the opposite occurs in SDS.
\end{abstract}

KEYWORDS (5): SDS, DTAC, PADA, MEUF, ultrafiltration, stripping

${ }^{1}$ Present Address: Department of Analytical Chemistry, Faculty of Pharmacy, Cukurova University, 01330 Adana, Turkey 


\section{Introduction}

The gold demand for electronic, catalytic and biological applications has recently experienced a rapid increase because of gold's unique physical and chemical properties [1-5]. In contrast with the rise of gold demand, mine production is considerably decreased [6, 7]. It has been shown that recovery of this metal, especially from electronic waste, can constitute a promising gold secondary source [8]. Actually, the gold concentration in mobile phone handsets is 300 $350 \mathrm{~g} / \mathrm{t}$ and in computer circuit boards is $200-250 \mathrm{~g} / \mathrm{t}$, which is tens of times higher than that in gold ores $(5-30 \mathrm{~g} / \mathrm{t})$ [8]. As a consequence, the separation and recovery of gold from e-waste has attracted much interest [9].

Gold recovery from industrial waste is performed by pyrometallurgy, hydrometallurgy, biohydrometallurgy techniques [7, 10-23]. However, it has been recognized since long time that growing demand for safety concern requires clean and efficient procedures [16]. In recent years the research on metal extraction based on metal entrapping systems has lead to the development of methods that could be favorably used to remove metal ions from waste streams. Previous studies have demonstrated that the use of micelles, as metal adsorbing agents, provides an efficient method to extract metal ions with high yields, up to $99.8 \%$ [24, 25]. With anionic surfactants, any cation present in solution will tend to be retained preferentially on the micelle surface by virtue of the electrostatic attraction. On the other hand, the metal, if in form of a negatively charged complex, will be trapped by cationic micelles. In the presence of non-ionic surfactants, metal ions can still be blocked on the (neutral) micelle surface if the surfactant heads can act like complexing ligands. The separation of the micellar pseudo-phase from the aqueous pseudo-phase is achieved by the ultrafiltration technique denoted as MEUF (Micellar Enhanced Ultrafiltration) using membranes with pore diameter smaller than that of the involved micelles [26]. MEUF offers many advantages (high yield extraction, less energy consumption and softer environmental impact) over classical methods as distillation and evaporation; however it lacks of selectivity, since it has been found that, using MEUF in its simplest version, metal ions as $\mathrm{Ca}^{2+}, \mathrm{Cu}^{2+}$, $\mathrm{Ni}^{2+}$ and $\mathrm{Zn}^{2+}$ are extracted by negatively charged surfactants with almost the same yields [27]. To enhance the selectivity of MEUF, a method has been developed that involves the addition of suitable metal complexing ligands (metal extractors) that bind to the micelle by hydrophobic interaction. This method, denoted as Ligand Modified Micellar Enhanced Ultrafiltration (LM-MEUF) is based on the ability of the added ligand to interact selectively with different metal ions [28]. 
In this paper we present the results of the extraction and recovery of gold using MEUF and LM-MEUF. The Au(III) complexing agent PADA has been used in LM-MEUF. A method for the $\mathrm{Au}(\mathrm{III}) / \mathrm{Cu}(\mathrm{II})$ separation is presented as well.

\section{Experimental Section}

\subsection{Materials}

Tetra chloroauric acid $\left(\mathrm{HAuCl}_{4} \cdot 3 \mathrm{H}_{2} \mathrm{O}\right)$, sodium dodecylsulphate (SDS), dodecyltrimethylammonium chloride (DTAC) and the metal extractor pyridine-2-azo-pdimethylaniline (PADA) were purchased from Sigma-Aldrich. Copper chloride, sodium chloride, magnesium sulphate, ammonia and hydrochloric acid were obtained from Fluka. All the reactants were analytical grade. Stock solutions of chemicals were prepared by dissolving weighed amounts of solid in water. The stock solution of PADA was prepared by addition of a suitable amount of ethanol to the solid in order to increase the ligand solubility and then diluting the resulting solution with water up to a ratio ethanol: water $=1: 100$. The concentration of $\mathrm{Cu}(\mathrm{II})$ stock solution was checked by titrating with EDTA. Doubly deionized water from a Millipore Milli-Q (Milan, Italy) water purification system was used to prepare the solutions and also as a reaction medium.

\subsection{Instrumentation and Methods}

The $\mathrm{pH}$ of the solution was measured with a combined glass microelectrode connected to a Metrohm 713 (Herisau, Switzerland) pH-meter and adjusted to the desired value by small additions of $\mathrm{HCl}$ or $\mathrm{NaOH}$.

The ultrafiltration studies were carried out in batch stirred cells (Amicon, model 8050), with a capacity of $50 \mathrm{ml}$ and an effective membrane area of $13.4 \mathrm{~cm}^{2}$. Ultrafiltration membranes made of regenerated cellulose (YM 3, Millipore) of diameter $44.5 \mathrm{~mm}$ and with a molecular weight cut off (MWCO) of 3000 daltons were used. The surfactant loss was not higher than the relevant cmc. Ultrafiltration membranes having higher MWCO have been tried, taking into account the aggregation number of SDS [29] and DTAC [30]. The change of MWCO resulted in a increase in the permeate flux but had only a minor role on the yield of metal rejection. The membranes were pre-treated and stored according to the method recommended by Millipore.

The extraction procedure is the following: the cell is initially loaded with $10 \mathrm{ml}$ of the investigated solution and then subject to ultrafiltration under an applied nitrogen pressure of $1 \mathrm{bar}$; the permeate solution contains the metal eventually not adsorbed on the micelle. 
The recovery procedure is as follows: the retentate is mixed with $10 \mathrm{ml}$ of stripping solution and then an ultrafiltration step is performed which allows separation of the metal-containing phase (the permeate) from the surfactant-containing phase (the retentate). Shortly after the conclusion of the procedure the ultrafiltration membranes were flushed with deionized water and, if necessary, they were regenerated according to the method recommended by Millipore. The amounts of the metal ion extracted and recovered were determined by the atomic absorption (AA) technique using a Perkin Elmer AAnalyst100 system and the samples were atomized in an air/acetylene flame; in the case of low concentrations of gold or copper a HGA-800 graphite furnace was employed. Hollow cathode lamps, specific for gold or copper were used. Calibration curves were performed using standard solutions (Sigma). The repeatability of concentration measurements was within $\pm 3 \%$.

The optical absorption measurements have been performed using a Perkin-Elmer Lambda 35 spectrophotometer (Üeberligen, Germany) with temperature control. Note that Au(III) absorbs in the UV [31], hence, the UV-vis spectrophotometric technique could have been used to quantify the gold content. However, spectrophotometry becomes unsuitable for low $\mathrm{Au}(\mathrm{III})$ concentrations $\left(\varepsilon=7.1 \times 10^{3} \mathrm{M}^{-1} \mathrm{~cm}^{-1}\right.$ at $\left.233 \mathrm{~nm}\right)$. So, AA has been preferred owing to its greater sensitivity. Moreover, AA can be used also for not UV-vis absorbing metal ions.

\section{Results and Discussion}

\subsection{Gold extraction by micelles}

Solutions of Gold in form of tetrachloroaurate, $\mathrm{AuCl}_{4}{ }^{-}$, were mixed with aqueous solutions containing the surfactant and eventually the metal extractor (PADA) and salt. The percent of metal retained by the surfactant, $R$, has been calculated using equation (1)

$$
\mathrm{R}=\left(1-\frac{\mathrm{M}_{\mathrm{p}}}{\mathrm{M}_{\mathrm{i}}}\right) \times 100
$$

where $M_{p}$ is the metal amount in the permeate and $M_{i}$ is the metal amount in the initial solution.

\subsubsection{Gold-PADA Complex Extraction by SDS (LM-MEUF)}

Some MEUF experiments have been performed in order to evaluate the eventual binding of Gold to SDS despite the lack of affinity of $\mathrm{AuCl}_{4}{ }^{-}$for the $\mathrm{SO}_{3}{ }^{-}$group. The values of $\mathrm{R}$ were near to zero in the entire range of the investigated SDS concentrations $(0.01<[$ SDS $]<0.06)$, in agreement with literature results [16]. 
The behavior is completely changed on adding the metal extractor PADA to the solutions of $\mathrm{AuCl}_{4}{ }^{-}$.

PADA behaves as a diprotic acid (Figure 1) with $\mathrm{pK}_{\mathrm{A} 1}=3.4$ and $\mathrm{pK}_{\mathrm{A} 2}=5.7$ in $\mathrm{SDS}$ and is totally adsorbed on the SDS micelles independently of the solution $\mathrm{pH}$ [32].

$\mathbf{L}$

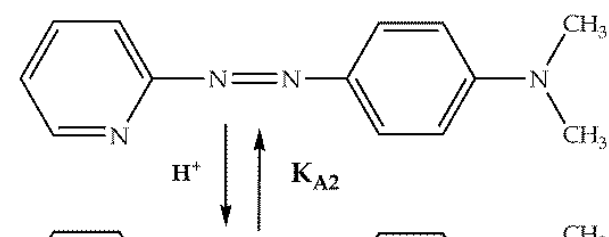

$\mathrm{HL}^{+}$
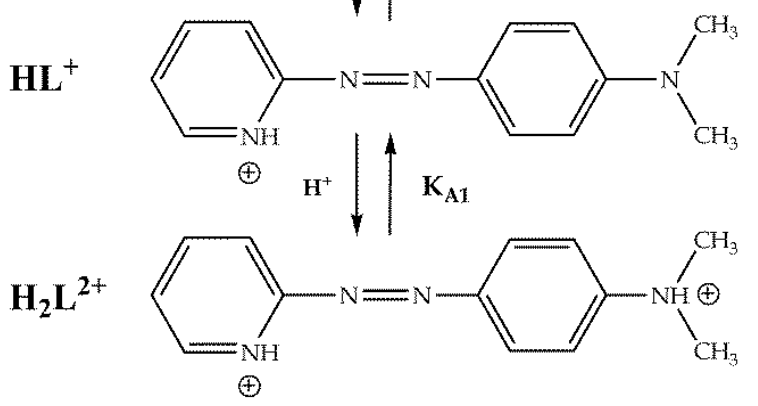

Figure 1 Pyridine-2-azo-p-dimethylaniline (PADA) in its neutral (L) and protonated forms $\left(\mathrm{HL}^{+}\right.$and $\left.\mathrm{H}_{2} \mathrm{~L}^{2+}\right)$.

PADA reacts with $\mathrm{Au}(\mathrm{III})$ giving a chelated species [31] according to the general reaction (2)

$\mathrm{AuCl}_{4}^{-}+\mathrm{L}-\mathrm{L}=\mathrm{AuCl}_{2} \mathrm{~L}_{-} \mathrm{L}^{+}+2 \mathrm{Cl}^{-}$

where the ligand has been denoted as L-L to point out that PADA is a bidentate agent able to bind the metal through the pyridine and the dimethyl-amino nitrogen atoms. Note that, while $\mathrm{AuCl}_{4}{ }^{-}$anion is repelled by SDS, the complex $\mathrm{AuCl}_{2} \mathrm{~L}-\mathrm{L}^{+}$can in principle be retained on the SDS surface owing to the hydrophobic properties of the ligand and to the positive charge. Table 1 shows that in the presence of PADA the retention yield is almost unitary and independent of the SDS concentration. Note that the addition of a relatively large amount of $\mathrm{NaCl}$ does not affect noticeably the retention level in spite of the decrease of the surface potential of SDS induced by the addition of sodium chloride [32]. This result indicates that the Au(III)-PADA complex is kept bound to SDS mainly because of the hydrophobic interactions provided by the ligand, while the charge effect is of minor importance. Table 1 also shows that the retention of gold stays very high, independently of the solution $\mathrm{pH}$ and 
does not experiences important changes in the $\mathrm{pH}$ range between 2.5 and 6.5, thus revealing that gold can be extracted under mild conditions.

Table 1 LM-MEUF: dependence of $\mathrm{Au}(\mathrm{III})$ retention on the [SDS], [NaCl] and $\mathrm{pH}$, in the presence of PADA; $[\mathrm{Au}]_{\text {initial }}=1 \times 10^{-4} \mathrm{M},[\mathrm{PADA}]=5 \times 10^{-4} \mathrm{M}$.

\begin{tabular}{cccc}
\hline [SDS] $(\mathrm{M})$ & {$[\mathbf{N a C l}](\mathrm{M})$} & $\mathbf{p H}$ & $\mathbf{A u}(\mathbf{I I I})$ retention $(\%)$ \\
\hline 0.016 & 0 & 3.5 & 92 \\
0.024 & 0 & 3.5 & 99 \\
0.032 & 0 & 3.5 & 100 \\
0.047 & 0 & 3.5 & 89 \\
0.016 & 0.1 & 3.5 & 100 \\
0.024 & 0.1 & 3.5 & 99 \\
0.032 & 0.1 & 3.5 & 100 \\
0.040 & 0.1 & 3.5 & 92 \\
0.047 & 0.1 & 3.5 & 86 \\
0.040 & 0 & 2.5 & 100 \\
0.040 & 0 & 3.5 & 100 \\
0.040 & 0 & 4.5 & 91 \\
0.040 & 0 & 5.5 & 93 \\
0.040 & 0 & 6.5 & 92 \\
\hline
\end{tabular}

\subsubsection{Gold extraction by DTAC (MEUF and LM-MEUF)}

Gold extraction has been performed using positively charged micelles of DTAC. The yield of metal retention for different surfactant concentrations in the absence and in the presence of $0.1 \mathrm{M} \mathrm{NaCl}$ is shown in Table 2. 
Table 2 Percentage of $\mathrm{Au}(\mathrm{III})$ retention by DTAC in the absence (MEUF) and in the presence of PADA (LM-MEUF) under different conditions; $[\mathrm{Au}]_{\text {initial }}=1 \times 10^{-4} \mathrm{M}$.

\begin{tabular}{ccccc}
\hline [DTAC] $(\mathrm{M})$ & [PADA] (M) & NaCl $(\mathrm{M})$ & $\mathbf{p H}$ & $\mathbf{A u}(\mathbf{I I I})$ retention (\%) \\
\hline 0.01 & 0 & 0 & 5.0 & 100 \\
0.02 & 0 & 0 & 5.0 & 100 \\
0.03 & 0 & 0 & 5.0 & 89 \\
0.04 & 0 & 0 & 5.0 & 90 \\
0.06 & 0 & 0 & 5.0 & 87 \\
0.01 & 0 & 0.1 & 5.0 & 101 \\
0.02 & 0 & 0.1 & 5.0 & 99 \\
0.03 & 0 & 0.1 & 5.0 & 96 \\
0.04 & 0 & 0.1 & 5.0 & 97 \\
0.06 & 0 & 0.1 & 5.0 & 96 \\
0.04 & 0 & 0 & 2.5 & 99 \\
0.04 & 0 & 0 & 3.0 & 99 \\
0.04 & 0 & 0 & 4.0 & 98 \\
0.04 & 0 & 0 & 5.0 & 96 \\
0.04 & 0 & 0 & 6.0 & 99 \\
0.01 & $5 \times 10^{-4}$ & 0 & 5.0 & 100 \\
0.02 & $5 \times 10^{-4}$ & 0 & 5.0 & 100 \\
\hline
\end{tabular}

Table 2 shows that the retention yields are very good and are independent of the level of DTAC present, the salt concentration and $\mathrm{pH}$. The conclusion drawn from the above results is that MEUF using DTAC allows $\mathrm{AuCl}_{4}{ }^{-}$to be extracted with high effiency, simply owing to the electrostatic attraction. However, some extraction experiments have been performed in the presence of PADA (Table 2). Note that, in this case, the species to be extracted is the Au(III)PADA complex, which, owing to its positive charge, should be repelled by the positive 
DTAC micelles. Nevertheless, the hydrophobic surface-ligand interactions are so strong that the complex is totally retained in spite of the electrostatic repulsion.

\subsection{Copper extraction using MEUF}

The above procedure was applied to extract $\mathrm{Cu}$ (II) from water using DTAC and SDS. Copper has been extracted from $\mathrm{CuCl}_{2}$ solutions using DTAC in the absence of added salts. $\mathrm{Cu}^{2+}$ ions are totally repelled by the DTAC micelles resulting in an extraction yield near to zero. In contrast, $\mathrm{Cu}(\mathrm{II})$ extraction using SDS provides excellent extraction yields. The results are reported in Table 3.

Table 3 Yields of MEUF extraction of Cu(II) by DTAC and SDS at different surfactant concentrations; $[\mathrm{Cu}]_{\text {initial }}=1 \times 10^{-4} \mathrm{M}, \mathrm{pH}=3.5$.

\begin{tabular}{cccc}
\hline [DTAC] & $\mathbf{C u}($ II) retention (\%) & [SDS] & $\mathbf{C u}($ II) retention $(\%)$ \\
\hline 0.01 & 3.0 & 0.01 & 97 \\
0.02 & 0.0 & 0.02 & 98 \\
0.03 & 0.0 & 0.04 & 100 \\
0.04 & 0.0 & 0.06 & 100 \\
0.05 & 0.0 & - & - \\
\hline
\end{tabular}

\subsection{Gold/Copper separation via MEUF}

Copper is the metal that most frequently is found in alloy with gold. The results shown above on the extraction of the single metals indicate that the separation of gold and copper from a mixture could be achieved. Two procedures for the separation of the components of $\mathrm{Au} / \mathrm{Cu}$ mixtures are presented in this section. First, the MEUF process has been applied to a mixture of $\mathrm{AuCl}_{4}{ }^{-}$and $\mathrm{Cu}^{2+}$ in the presence of $0.04 \mathrm{M} \mathrm{DTAC}$ at different $\mathrm{pH}$ values. While positively charged copper ions are not adsorbed and pass through the ultrafiltration membrane in the aqueous pseudo-phase, the negatively charged gold ions are retained on the micellar pseudophase, thanks to the electrostatic attraction. The results are very good both if equimolar $\mathrm{Au} / \mathrm{Cu}$ mixtures are analysed (circles in Figure 2A), and if gold excess (triangles) or copper excess (stars) are present. 

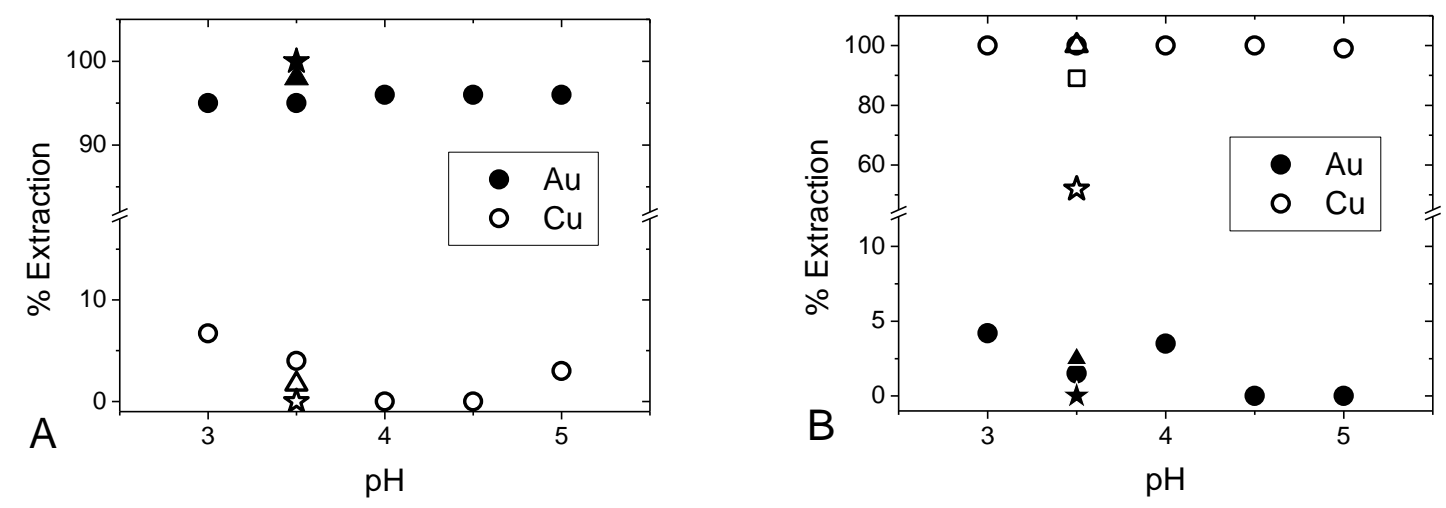

Figure 2 MEUF separation of $\mathrm{Cu}(\mathrm{II})$ (open symbol) and $\mathrm{Au}(\mathrm{III})$ (full symbol) present in a mixture at different $\mathrm{pH}$ values using: (A) $0.04 \mathrm{M}$ DTAC and (B) $0.04 \mathrm{M}$ SDS. Circles: $[\mathrm{Au}]_{\text {initial }}=[\mathrm{Cu}]_{\text {initial }}=1 \times 10^{-4} \mathrm{M}$; triangles: $[\mathrm{Au}]_{\text {initial }}=9 \times 10^{-4} \mathrm{M},[\mathrm{Cu}]_{\text {initial }}=1 \times 10^{-4} \mathrm{M}$; stars: $[\mathrm{Au}]_{\text {initial }}=1 \times 10^{-4} \mathrm{M},[\mathrm{Cu}]_{\text {initial }}=9 \times 10^{-4} \mathrm{M}$; the open square refers to an experiment in $0.1 \mathrm{M}$ SDS, $[\mathrm{Au}]_{\text {initial }}=1 \times 10^{-4} \mathrm{M},[\mathrm{Cu}]_{\text {initial }}=9 \times 10^{-4} \mathrm{M}$.

The process of component separation in the $\mathrm{AuCl}_{4}{ }^{-} / \mathrm{Cu}^{2+}$ mixture has been investigated also using the negatively charged SDS micelles. Oppositely to the DTAC case, the $\mathrm{AuCl}_{4}{ }^{-}$ions passed through the ultrafiltration membrane while the $\mathrm{Cu}^{2+}$ ions remain blocked in the micellar pseudo-phase above the membrane. Figure 2B shows that also using SDS the separation of the two metals is very effective, independently of the medium acidity. The yields are very good both if equimolar $\mathrm{Au} / \mathrm{Cu}$ mixtures are analysed (circles in Figure 2B), and if gold excess (triangles) is present. Under conditions of copper excess (stars) the $\mathrm{Cu}$ (II) metal ion retention by SDS lowers to $52 \%$, but this value can be enhanced to $89 \%$ if the SDS concentration is increased from $0.04 \mathrm{M}$ to $0.1 \mathrm{M}$ (square). This behavior suggests that only limited number of $\mathrm{Cu}(\mathrm{II})$ ions can be allocated on the SDS micelle surface.

The above described procedure shows that gold and copper can be separated by MEUF with excellent yields using either SDS or DTAC, the latter showing the best results under conditions of copper excess.

\subsection{Gold Recovery from Micelles}

Further experiments have been performed in order to find a convenient method allowing the recovery of the gold adsorbed on the micellar phase. A suitable stripping agent was added to 
the retentate and the resulting solution was subject to ultrafiltration. Different stripping agents have been tested, such as salts or acid which reduce the surface potential of the micelles, and $\mathrm{NH}_{3}$, in order to convert the negatively charged $\mathrm{AuCl}_{4}{ }^{-}$into the positively charged $\mathrm{Au}\left(\mathrm{NH}_{3}\right)_{4}{ }^{3+}$ complex which, in the case of metal adsorption on DTAC, is expelled from the micellar to the aqueous phase by virtue of its positive charge. The percentage of gold recovered has been determinated by equation (3)

$\%$ Re cov ery $=\frac{M_{\text {Permeate }}}{M_{\text {Initial }}} \times 100$

The results are reported in Table 4 .

Table 4 Percentage of recovery of $\mathrm{Au}(\mathrm{III})$ from DTAC using different stripping agents; $[\mathrm{Au}]_{\text {initial }}=1 \times 10^{-4} \mathrm{M},[\mathrm{DTAC}]=0.02 \mathrm{M}$.

\begin{tabular}{|c|c|c|c|c|}
\hline $\begin{array}{c}{[\mathrm{NaCl}]} \\
(\mathrm{M})\end{array}$ & $\begin{array}{c}{\left[\mathrm{Na}_{2} \mathrm{SO}_{4}\right]} \\
(\mathrm{M})\end{array}$ & $\begin{array}{c}{\left[\mathbf{N H}_{3}\right]} \\
(\mathrm{M})\end{array}$ & $\begin{array}{c}{[\mathrm{HCl}]} \\
(\mathrm{M})\end{array}$ & \% Recovery \\
\hline- & 0.5 & - & - & 17 \\
\hline 0.3 & - & - & - & 5 \\
\hline 0.5 & - & - & - & 20 \\
\hline 1 & - & - & - & 31 \\
\hline 1.5 & - & - & - & 5 \\
\hline 2 & - & - & - & 2 \\
\hline- & - & - & 0.1 & 20 \\
\hline- & - & - & 0.2 & 33 \\
\hline- & - & - & 0.3 & 31 \\
\hline- & - & 0.1 & - & 32 \\
\hline- & - & 0.2 & - & 18 \\
\hline- & - & 0.2 & - & 16 \\
\hline- & - & 0.5 & - & 17 \\
\hline- & - & 1 & - & 36 \\
\hline 0.5 & - & 0.2 & - & 81 \\
\hline 1 & - & 0.2 & - & 86 \\
\hline 2 & - & 0.2 & - & 85 \\
\hline
\end{tabular}


Table 4 shows that the percentage of recovery by salt is rather low. The addition of $\mathrm{HCl}$ also induces rejection of gold from the DTAC surface but the yield of recovery does not exceed that obtained using $\mathrm{NaCl}$. It should be noted, however, that experiments with acid were limited to $0.3 \mathrm{M}$ because a higher acidity levels can damage the ultrafiltration membrane. Replacement of salt by ammonia provides a little improvement of the recovery yield. On the other hand, in the presence of mixtures of $\mathrm{NH}_{3}$ and $\mathrm{NaCl}$, the recovery yield is largely improved. The observed effect can be explained with the reduction of the surface potential of DTAC operated by $\mathrm{NaCl}$ [32] which makes weaker the electrostatic attraction between DTAC and $\mathrm{AuCl}_{4}{ }_{4}^{-}$. Moreover, the conversion of $\mathrm{AuCl}_{4}{ }^{-}$to $\mathrm{Au}\left(\mathrm{NH}_{3}\right)_{4}{ }^{3+}$ and the consequent repulsion of the latter complex provide the high recovery yields obtained.

An attempt has been made to recover gold from the system SDS-Au-PADA by adding to the retentate different concentrations of $\mathrm{NaCl}, \mathrm{HCl}$ and $\mathrm{NH}_{3}$. The results are reported in Table 5 which shows that the recovery yield is extremely poor under all the investigated conditions

Table 5 Percentage of $\mathrm{Au}(\mathrm{III})$ recovery from SDS in the presence of PADA by addition of stripping agents as respectively $\mathrm{NaCl}, \mathrm{HCl}$ and $\mathrm{NH}_{3}$.

\begin{tabular}{cccc}
\hline$[\mathrm{NaCl}]$ & {$[\mathrm{HCl}]$} & {$\left[\mathrm{NH}_{3}\right]$} & $\begin{array}{c}\text { Total \% } \\
\text { Recovery }\end{array}$ \\
$(\mathrm{M})$ & $(\mathrm{M})$ & $(\mathrm{M})$ & 0 \\
0.10 & 0 & 0 & 0.80 \\
0.20 & 0 & 0 & 1.90 \\
0.50 & 0 & 0 & 0.10 \\
0 & 0.020 & 0 & 0.01 \\
0 & 0.1 & 0 & 1.2 \\
0 & 0 & 0.2 & 1.2 \\
0 & 0 & 0.5 &
\end{tabular}

\section{Conclusions}

The extraction of $\mathrm{Au}(\mathrm{III})$ using the MEUF procedure in the presence of DTAC provides excellent yields and, under particular conditions, good recovery yields. It should be noted that addition of salts and even of strong acid is not sufficient to strip the gold out of the micelle 
surface. On the other hand, addition of ammonia, as a stripping agent, does not improve recovery of the metal from DTAC. The best results have been obtained using a mixture of ammonia and sodium chloride, where the decrease of the surface potential induced by the salt and the complexing power of ammonia act in the same direction.

The LM-MEUF procedure with SDS, yields excellent gold extraction thanks to the hydrophobic properties of PADA but the subsequent recovery process provides, in contrast, poor yields. An interpretation of this behaviour could reside on the fact that the Au-PADA complex is too strongly adsorbed on the SDS surface owing to the combined action of hydrophobic forces and charge that act both in the direction of increasing the retention of the Au-PADA complex on the micelle.

The excellent yields of $\mathrm{Au}(\mathrm{III}) / \mathrm{Cu}$ (II) separation achieved both with DTAC and SDS could open favourable perspectives in the extraction of precious metals from mixtures using simple MEUF.

Acknowledgements: The financial support by Obra Social "la Caixa", project OSLC-2012007, and by the Ministerio de Economia y Competividad - Gobierno de España, project MINECO CTQ2014-58812-C2-2-R, are gratefully acknowledged. 


\section{REFERENCES}

[1] C.W. Corti, R.J. Holliday, D.T. Thompson, Developing new industrial applications for gold: Gold nanotechnology, Gold. Bull. 35 (2002) 111-136.

[2] A.S.K. Hashmi, G.J. Hutchings, Gold catalysis, Angew. Chem. Int. Edit. 45 (2006) 78967936.

[3] A. Arcadi, Alternative synthetic methods through new developments in catalysis by gold, Chem. Rev. 108 (2008) 3266-3325.

[4] S.A.C. Carabineiro, B.E. Nieuwenhuys, Adsorption of small molecules on gold single crystal surfaces, Gold. Bull. 42 (2009) 288-301.

[5] C. Gabbiani, F. Scaletti, L. Massai, E. Michelucci, M.A. Cinellu, L. Messori, Medicinal gold compounds form tight adducts with the copper chaperone Atox-1: biological and pharmacological implications, Chem. Commun. 48 (2012) 11623-11625.

[6] S. Akita, L. Yang, H. Takeuchi, Solvent extraction of gold(III) from hydrochloric acid media by nonionic surfactants, Hydrometallurgy 43 (1996) 37-46.

[7] Y.F. Shen, W.Y. Xue, Recovery palladium, gold and platinum from hydrochloric acid solution using 2-hydroxy-4-sec-octanoyl diphenyl-ketoxime, Sep. Purif. Technol. 56 (2007) 278-283.

[8] C. Hageluken, C.W. Corti, Recycling of gold from electronics: Cost-effective use through 'Design for Recycling', Gold. Bull. 43 (2010) 209-220.

[9] C. Mack, B. Wilhelmi, J.R. Duncan, J.E. Burgess, Biosorption of precious metals, Biotechnol. Adv. 25 (2007) 264-271.

[10] S. Syed, Recovery of gold from secondary sources-A review, Hydrometallurgy 115 (2012) 3051.

[11] J.R. Cui, L.F. Zhang, Metallurgical recovery of metals from electronic waste: A review, J. Hazard. Mater. 158 (2008) 228-256.

[12] J.O. Marsden, C.I. House, The Chemistry of Gold Extraction, Littleton, 2006.

[13] A. Wolowicz, Z. Hubicki, Adsorption characteristics of noble metals on the strongly basic anion exchanger Purolite A-400TL, J. Mater. Sci. 49 (2014) 6191-6202.

[14] M. Iglesias, E. Antico, V. Salvado, Recovery of palladium(II) and gold(III) from diluted liquors using the resin duolite GT-73, Anal. Chim. Acta 381 (1999) 61-67.

[15] J.L. Cortina, R.M. Kautzmann, R. Gliese, C.H. Sampaio, Extraction studies of aurocyanide using Macronet adsorbents: physico-chemical characterization, React. Funct. Polym. 60 (2004) 97107.

[16] S. Akita, L. Yang, H. Takeuchi, Micellar-enhanced ultrafiltration of gold(III) with nonionic surfactant, J. Membrane Sci. 133 (1997) 189-194.

[17] M. Cox, A.A. Pichugin, E.I. El-Shafey, Q. Appleton, Sorption of precious metals onto chemically prepared carbon from flax shive, Hydrometallurgy 78 (2005) 137-144.

[18] A.B. Farag, M.H. Soliman, O.S. Abdel-Rasoul, M.S. El-Shahawi, Sorption characteristics and chromatographic separation of gold (I and III) from silver and base metal ions using polyurethane foams, Anal. Chim. Acta 601 (2007) 218-229.

[19] G. Hilson, A.J. Monhemius, Alternatives to cyanide in the gold mining industry: what prospects for the future, J. Clean. Prod. 14 (2006) 1158-1167.

[20] H. Narita, M. Tanaka, K. Morisaku, T. Abe, Extraction of gold(III) in hydrochloric acid solution using monoamide compounds, Hydrometallurgy 81 (2006) 153-158.

[21] J. Yang, F. Kubota, Y. Baba, N. Kamiya, M. Goto, Application of cellulose acetate to the selective adsorption and recovery of Au(III), Carbohyd. Polym. 111 (2014) 768-774.

[22] J. Baker, R.J. Baker, C. Schulzke, Perfluorinated oxygen- and sulfur-containing compounds as extractants for gold(III), Gold. Bull. 44 (2011) 79-83.

[23] W.J. Lu, Y.M. Lu, F. Liu, K. Shang, W. Wang, Y.Z. Yang, Extraction of gold(III) from hydrochloric acid solutions by CTAB/n-heptane/iso-amyl alcohol/Na2SO3 microemulsion, J. Hazard. Mater. 186 (2011) 2166-2170. 
[24] J. Klepac, D.L. Simmons, R.W. Taylor, J.F. Scamehorn, S.D. Christian, Use of LigandModified Micellar-Enhanced Ultrafiltration in the Selective Removal of Metal-Ions from Water, Separ. Sci. Technol. 26 (1991) 165-173.

[25] L. Ghezzi, B.H. Robinson, F. Secco, M.R. Tine, M. Venturini, Binding of Pd(II) to Pada in water/micellar system: Complex formation, kinetics in water and DTAC solution, Colloids Surf. A 292 (2007) 139-147.

[26] S. Akita, L.P. Castillo, S. Nii, K. Takahashi, H. Takeuchi, Separation of Co(II)/Ni(II) via micellar-enhanced ultrafiltration using organophosphorus acid extractant solubilized by nonionic surfactant, J. Membrane Sci. 162 (1999) 111-117.

[27] S.D. Christian, J.F. Schameron, J.H. Harwell, Surfactant Based Separation Process, NewYork, 1989.

[28] T. Biver, C. Paoletti, F. Secco, M. Venturini, Extraction, separation and recovery of palladium and platinum by a kinetic method combined with ultrafiltration, Colloids Surf. A 441 (2014) 466-473.

[29] Y. Moroi, R. Humphry-Baker, M. Gratzel, Determination of micellar aggregation number of alkylsulfonic acids by fluorescence quenching method, J. Coll. Int. Sci. 119 (1987) 588-591.

[30] B.L. Bales, R. Zana, Characterization of micelles of quaternary ammonium surfactants, as reaction media I: Dodeclytrimethylammonium bromide and chloride, J. Phys. Chem. B 106 (2002) 1926-1939.

[31] S. Aydinoglu, T. Biver, F. Secco, M. Venturini, The Kinetics of Gold(III) Extraction by Pyridine-2-azo-p-dimethylaniline in Water and in Micellar Systems, Colloids Surf. A Accepted for publication (2015)

[32] S. Aydinoglu, T. Biver, F. Secco, M. Venturini, Effects of micelle nature and concentration on the acid dissociation constants of the metal extractor PADA, Colloids Surf. A 461 (2014) 303-309. 


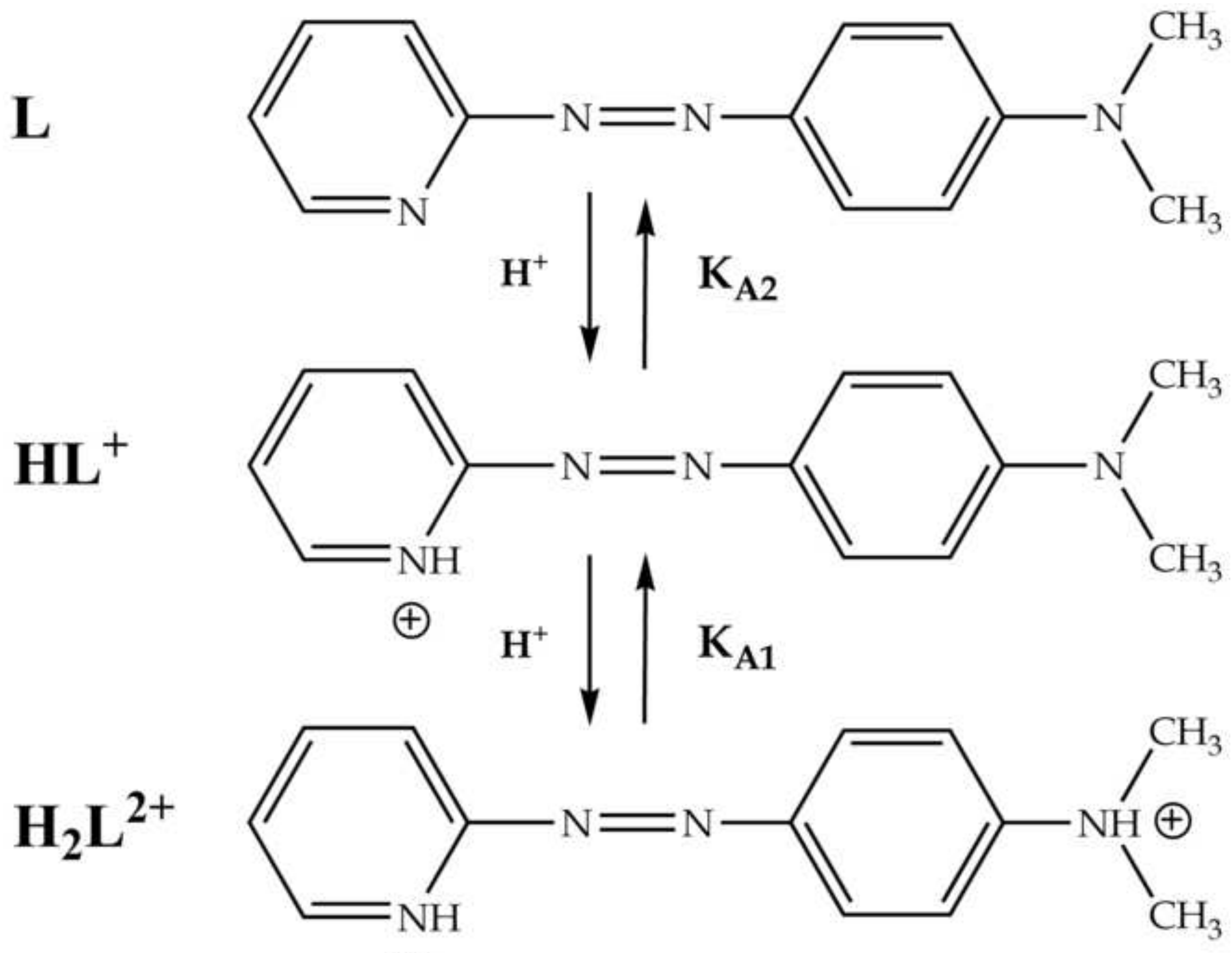

$\oplus$ 


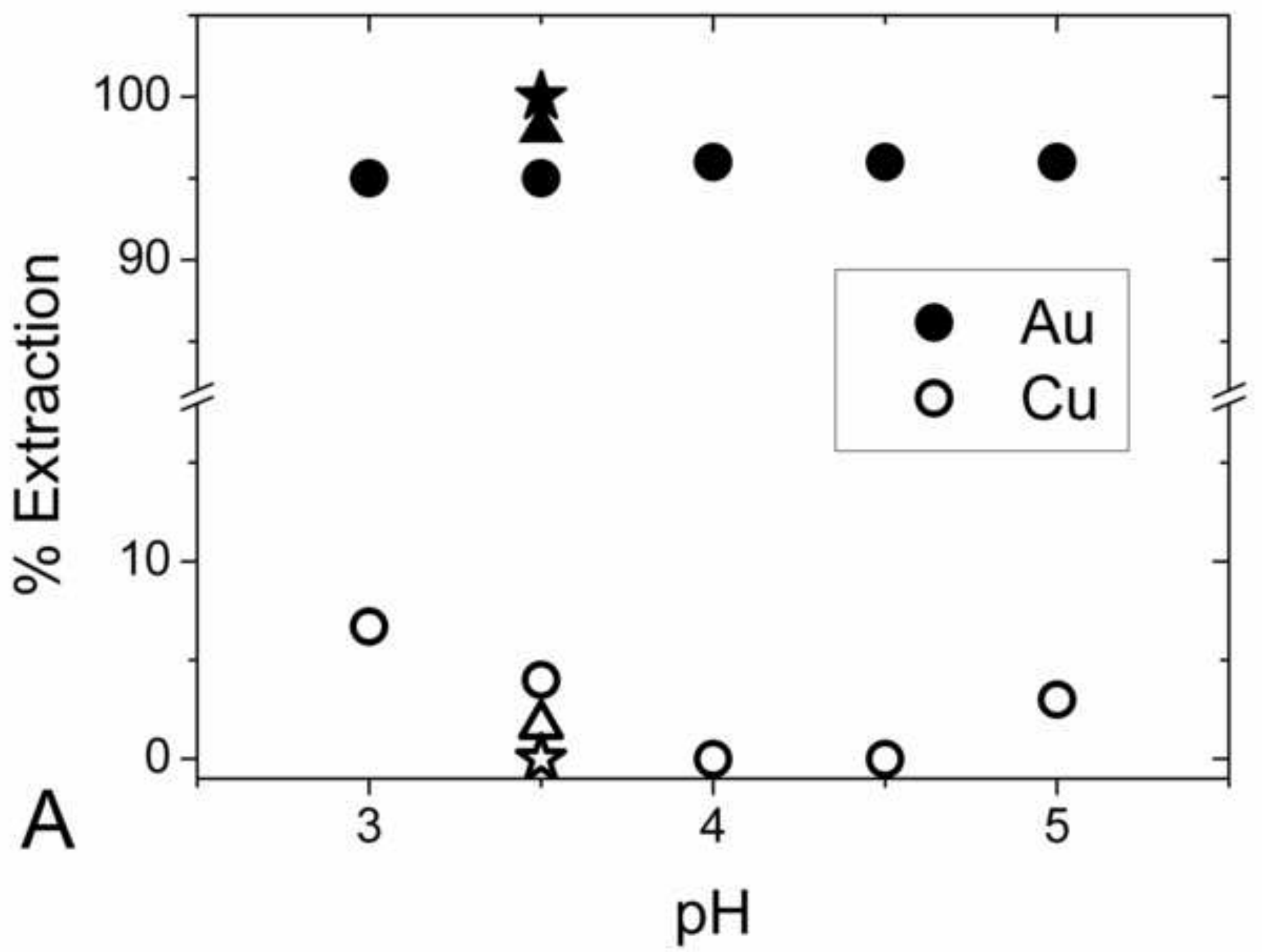




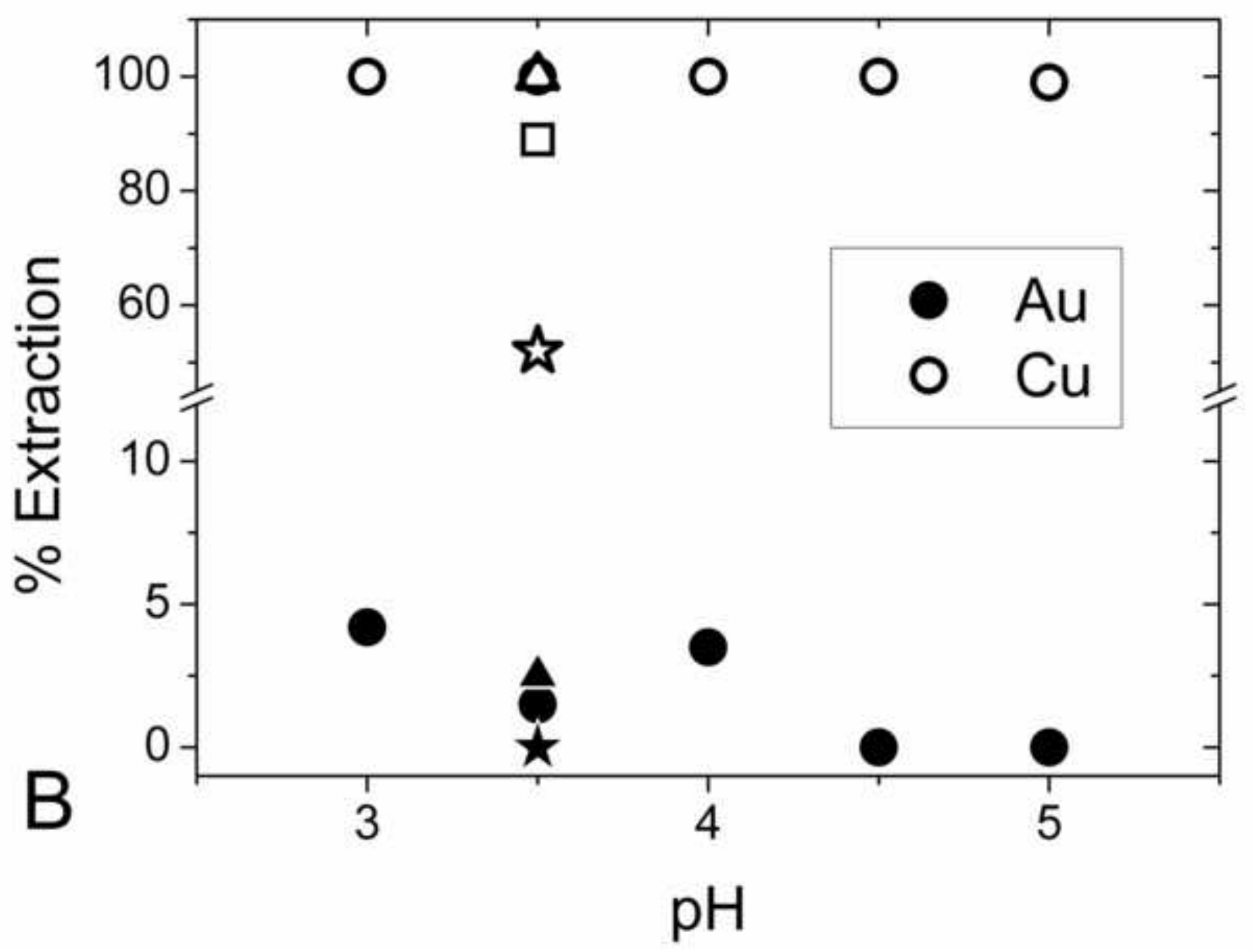

